\title{
Improving the Effectiveness of Evaluation in Rural Development Projects*
}

\section{B. H. Kinsey}

Two multilateral development agencies-the FAO and the World Bank-have recently completed major reviews of their own and others' efforts to promote rural and agricultural development through a broad spectrum of projects and programmes in a wide range of countries. Despite large investments of manpower and resources in reviewing such projects, many of the conclusions contained in the two volumes are only tentative. As the FAO volume laments, "it has still not been possible to use effectively the results of the numerous project reviews as feedback for future programming or project formulation or for the development of an evaluation methodology."1

Using the experience of the projects, the two reviews sought to identify the nature of rural development and how this development might best be promoted. They found almost universally, however, that such experience has been inadequately documented, if documented at all, and that in many important policy areas only superficial conclusions are possible. It is obvious from the reviews that many practical lessons, often painfully learned only after years of trial and error, have been lost simply because they had not been systematically recorded in the field. It is equally obvious that many projects are not successful because preconceived notions of the crucial constraints in a particular situation have been embodied in an excessively rigid project design; when different problems or constraints are subsequently identified, sometimes after prolonged and frustrating attempts to implement an inappropriate strategy, it is either too late to make the needed changes and/or the project design is too inflexible to permit them to be made.

Many of the difficulties and contradictions of the project-style ${ }^{2}$ approach to rural development stem from the requirement that projects must usually

\footnotetext{
* Derived in part from Rural Development in Malawi: A Review of the Lilongwe Land Development Program, Studies in Employment and Rural Development No. 9, Development Economics Department, IBRD, September 1974, prepared by Economics Department, IBRD, September 1974, prepared by and as part of the Bank's African Rural Development Study. The views expressed represent those of the author and not necessarily those of the Bank.

1 Review of Field Programmes 1974-75, FAO, Rome, 1975.

2 As disting! ished from a programme-style approach, usually operating in a larger scale. Many so-called 'programmes', however, consist simply of a sequence of projects.
}

be 'bankable', i.e. designed so that an internal rate of return can be calculated. The dominance of this single criterion for project 'evaluation' has a strong influence on the nature of projects: typically, they operate (above some threshold scale) for a limited but specified period of time by concentrating resources, including management, in a defined geographical area to achieve set objectives. The objectives will normally be a mix of those conceptually easy to quantify and those conceptually difficult to quantify, usually with greater emphasis on the former (crop yields, export earnings, net returns, boreholes drilled, miles of road built, etc.) and probably with little more than a mention given to the latter (local participation, institution building, income distribution, changes in 'attitudes' and motivations of farmers, creation of skills and enhancement of abilities in staff, etc.). Since the targets used at appraisal to estimate the rate of return are linked to a time scale and, moreover, are based on technical feasibility and economic viability for a predetermined approach, project management is under pressure not only to meet targets but also to meet them by a certain time and in a certain way. This pressure is antithetical to a flexibility which allows earlier stages of project implementation to contribute to shaping policies and programmes for later stages, in which the first conscious objective of a project is to identify constraints and priorities and to devise appropriate methods of dealing with local problems, and in which the pace of implementation is geared to the development of local human and institutional capabilities.

In her summing up of the World Bank review, Uma Lele notes that "substantially greater planning effort is necessary than was possible in most of the programs reviewed if effectiveness is to be maximized."3 She also recommends an approach involving "planning based on systematic acquisition of local knowledge and flexibility in the course of implementation" and notes that this recommendation "involves beginning programs with only the few simplest interventions to remove the most critical constraints, and allows the programs to evolve in scope through time-phasing of activities." In its recent rural development policy paper, the World Bank recognizes the in-

3 Uma Lele, The Design of Rural Development: Lessons from Africa, John Hopkins University Press, Baltimore, 1975. 
adequacy of information concerning the ways in which rural development may be accelerated and calls for a high priority to be given to conducting research and gathering information. ${ }^{4}$

It is impossible to overstress that relevant research must begin at the project level, and project evaluation units (PEUs), built into the project concerned, have been tried with varying degrees of success in a wide variety of circumstances. It is this writer's experience however, that not enough thought has gone into the aims and organization of, and even the need for, PEUs. In consequence they have been asked to perform work they are not equipped to do, have been badly organized and located, have been swamped with unanalysed data and have in many cases produced 'evaluations' with only a marginal, if any, value.

\section{The Nature of the Demand for Project Evaluation Studies}

Three different 'audiences' for evaluation studies may be identified:

(1) The lending or donor agency. The primary concerns of this agency are to ensure that the terms of a loan are being adhered to and/or that a project is generating benefits more or less in accordance with those projected at appraisal. Chief emphasis is placed upon rate-of-return/ cost-benefit criteria and disbursement scheduling.

(2) The borrowing or recipient government. The borrowing government also has an interest in seeing that the terms of a loan are met and that benefits are resulting as expected, but an equally important concern arises from the need to prepare loan submissions for new projects and additional phases of existing projects.

(3) The project management. Project management is involved on a day-to-day and month-to-month basis with the implementation of a project design and with progressive modification of design to ensure that short-term tactics are consistent with longer-term goals.

Each of these three authorities generates its own demand for information and data. Though to a certain extent these demands are congruent, it is the divergence among them which creates problems for PEUs and for effective evaluation. It is clear from the experience of a number of projects that while the quality of planning and implementation is severely constrained by the shortrun data supply, substantial resources are being devoted to data production without any-or only

4 Rural Development: Sector Policy Paper, IBRD, Washington, 1975. partial-specification of the nature of the users' demand for that data.

\section{The Objectives of Rural Development Projects and the Evaluation Role}

While each individual project will have its own hierarchy of specific objectives, it would probably not misrepresent too many projects if the basic goal of rural development projects is here taken to be the generation of self-sustaining increases in the level of living for a large proportion of the target population. Each part of this general goal is given separate emphasis below, for each has different implications for a range of activities which, for the moment, are lumped together as evaluation.

The generation of benefits relates to a project's role as a catalyst or a stimulus for change, while self-sustaining relates to the permanence of the stream of benefits which, in turn, hinges upon a project's ability to impart the capacity to generate benefits to local institutions and personnel. Increases in the level of living may loosely be characterized as the output side of the rural development equation. Depending upon the nature and design of a project, the increases aimed for may be expressed as relatively precise magnitudes of given variables - such as yields, incomes or exports-or they may be expressed in more general terms-such as the establishment of a settled pattern of agriculture-or as some combination of the two. What is clear, however, is that each class of objectives must be evaluated in different terms and that some objectives will be extraordinarily difficult to evaluate in any terms. Finally, expressing concern for the distribution of benefits and for the equity and overall impact of rural development projects, the general goal stipulates that benefits shall accrue for a large proportion of the target population.

As noted above, goals may be qualitative rather than quantitative; that is, they may indicate the direction in which efforts should move rather than give an indication of the strength of the movement. They may also conflict, forcing evaluation to be made in terms of a variety of internally inconsistent or contradictory variables, and preventing any effective assessment of the project as a whole. Therefore, in addition to judging whether the more highly specified goals are being met, it may be necessary to take into account a host of other direct and indirect effects of project activities.

To relate the evaluation function to project structure, a project should be conceptualized as operating at several different levels. At the first-or 
project-level, goals are spelled out in broad terms, e.g. raising family incomes by a given percentage, doubling crop yields, etc. Evaluation at this level involves finding measures of overall project effectiveness, which will relate all project effects and costs to project goals.

At the second-or section/division-level, the subgoals which, when met in a coordinated and phased manner, enable project goals to be attained, are spelled out. These sub-goals, to a large degree, define the functions of the various sections within a project. Activities will be performed by each section and the production or other targets of each activity are specified, at least in general terms, in the annual budgets set out in the appraisal reports. These sub-goals might include, for example, the issuing of inputs by the credit section sufficient to grow a specified number of acres of a given crop at a certain input intensity. The related sub-goal for the extension section might be to conduct training activities or to make field visits to ensure that the inputs are used correctly, while the section responsible for marketing might be expected to make arrangements for moving and storing the anticipated incremental output.

At the third level of operation, targets are set for each activity carried out by the different sections. These will be expressed in terms of forecasts of inputs and outputs for each type of activity. Evaluation at this level, as well as at the section level, involves the identification of performance indicators-variables considered to be of high priority in connection with specified goals-capable of measuring the efficiency of the different sections and activities within sections.

Three separate facets of the efforts involved in data collection and analysis roughly parallel the three levels of project operation. These are:

(1) Evaluation. Used in relation to measuring performance at the first level, i.e. overall project effectiveness. The application of a broad perspective concentrating on issues of priority, significance and validity of a project as a whole, replicability under different circumstances, and determination of the cost-benefit relationships relative to alternative approaches.

(2) Monitoring. Used primarily in relation to measuring performance at the second level, i.e. both effectiveness and efficiency of the input delivery system. This involves the periodic inspection of indicator data to identify developing problems or possible opportunities, the assessment of successes and failures, and the prompt reporting of findings and recommendations to project management.
(3) Recording. Used to determine levels of activity of all project components. Involves the periodic collection of data on a series of pertinent indicator variables, assembling the data, and reporting them in a uniform and comparable manner.

These distinctions are not mutually exclusive; they imply certain linkages and overlapping. They are, however, helpful in determining objectives for PEUs in carrying out certain functions.

\section{Two Types of Project Monitoring}

Different types of project monitoring will have different implications for the size, organization and operations of PEUs. Two types can be distinguished immediately.

The first, which we may call Type I monitoring, is intended to supply information continuously to focus the attention of project management and review missions on critical aspects of project development. Type I monitoring seeks to assemble and analyse only enough detailed information to permit judgments about specific aspects of the project in a rather narrow sense. A Type I monitoring capability should be installed in all projects. Elements included under Type I will be discussed in the section on project management information systems which follows.

In contrast, Type II monitoring would look at the operations of a given project in greater detail, with more attention to longer-term evaluation and research questions. Type II monitoring implies either a large and well-staffed PEU with access to data-processing facilities, or the extensive use of other research institutions, possibly operating with supplementary funds provided by external agencies.

Data from Type II monitoring operations, when analysed, will not only permit a clearer understanding of the effects of specific projects on given populations, but will also suggest more general conclusions regarding the consequences of a certain type of project on overall rural development, land-use patterns, generation of public finance from the rural sector, income growth and distribution, etc. The complexity of much of the Type II evaluation suggests the advisability of using interdisciplinary teams of researchers, particularly in areas lying outside strictly agro-economic studies. Affiliation with a local or overseas research institution may be the best way in which to introduce the interdisciplinary element.

While Type I monitoring involves primarily collecting and reporting information of a statistical and/or financial nature, Type II monitoring is 
concerned with the collection and analysis of broad economic data-plus what might be termed social-institutional information-which are both quantitative and qualitative in nature. This latter type of information is difficult and expensive to obtain and even more difficult to evaluate. Both the quantitative and qualitative data are open to different interpretations; and a neutral evaluative judgment on the part of project staff may be difficult to obtain because there is a strong tendency to introduce a favourable bias whenever ambiguity exists. These considerations suggest also that in certain instances Type II evaluation might better be done by an outside acency.

Funding agencies should clearly indicate the types of monitoring and evaluation a PEU is expected to perform, and these should be written into the project agreement. For most projects a very modest Type I unit will suffice to monitor the development of the project and conduct occasional small-scale surveys. For the more elaborate, innovative or costly projects, it may be desirable to include a Type II unit to evaluate certain aspects or even the whole project in considerable depth and detail, in addition to the ordinary monitoring function.

\section{Evaluation Units as Management Information Systems}

For most projects, evaluation will be relevant principally as an element of operational control, i.e. as an aid to administrative effectiveness and efficiency; hence it has been suggested that a Type I monitoring capability be established in all rural development projects.

Project managers disburse considerable amounts of funds, often under very difficult conditions. The managerial task is made even more arduous by multiple, ill-defined and sometimes conflicting goals, by the conflicts created by the parastatal nature of projects, by the human relations problems associated with a highly disparate staff, and by intricate problems of multiple financing, logistics and administrations. PEUs can make a valuable contribution to improving project management if such a role is clearly specified at the outset; they are far less likely to be an effective aid to project management when their role is not explicit or when they are called upon to perform tasks for which they are not equipped.

It is inevitable that modifications to original operating procedures and specifications will occur at various stages as a project proceeds. One of the chief virtues of building PEUs into projects is that, by constantly monitoring the pace and pattern of development and scanning selected indi- cator variables, they can test the critical variables and assumptions and recommend modifications as a project goes along.

Only a small PEU (consisting of one evaluation officer, perhaps an economist or business administration graduate, and a few clerical staff) need be built into a project for the purpose of supplying information for project management. It should be realized, however, that even with a small unit there is a danger of collecting too much data. Every effort, therefore, should be made to identify key progress indicators, and only those capable of encapsulating the performance of crucial elements should be selected for regular monitoring in a Type I management information system. It is likely that both externally and government-funded research will be required to permit the identification of such key elements.

To provide an overview of the programmes of the various sections and to relate these to overall project goals, it will be necessary to monitor certain quantitative indicator variables at the section level and to relate these to the qualitative information. This will form the basis for periodic reports to be prepared by the PEU for project management. In addition to indicating current project status, these reports will serve several other objectives, including:

(i) contributing to the establishment of a data base for future reference as well as for management decision-making;

(ii) enhancing coordination among the different sections of a project;

(iii) permitting problems to be anticipated so that solutions can be deliberated rather than thrown up in reaction to unforeseen crises;

(iv) suggesting alternative approaches or combinations of activities which may be more effective or efficient than those currently in practice.

\section{Phasing the Introduction of Project Evaluation Units}

In most instances, PEUs appear to have been placed in projects too late to collect baseline or control data that are truly representative of preproject conditions. By the time a PEU is established and organized sufficiently to run its first comprehensive survey or census, the project typically will have had field operations under way for a year or more. If there has been a strong positive response to project activities in the first year or so of operation, then use of these data as a baseline will understate the actual benefits from the project. There appears to be, moreover, a significant trade-off between the timely effort 
expended in collecting and analysing baseline data and the amount of modification required in project operations at a later date, as the relative paucity of baseline data is the main determinant of the number of assumptions made at the proposal and appraisal stages.

Even in the fortunate but rare situation where ample and reliable pre-project data are available, it is desirable to establish a PEU as early as possible in order to detect incipient difficulties and identify possible opportunities which may have been overlooked in the project proposal. An additional advantage resulting from the early introduction of PEUs is that of establishing an effective project record-keeping and documentation system.

\section{Conclusions}

PEUs can be entirely effective only when the demand for information is thoroughly and accurately specified, and when they are provided with the resources to permit them to supply the information demanded. There has been a tendency for aid agencies, governments and project managers to underestimate the practical difficulties of even seemingly simple data-gathering exercises; con- sequently costs have been-and continue to beunderestimated, and insufficient attention has been given to minimizing the amount of data collected for decision-making purposes.

The value of PEUs' evaluation function can be increased if, first, the three data-using groups clarify the nature of their demand for information. Second, it should be recognized by the aid agencies and by national governments that the true costs of existing evaluation systems in rural development projects have been underestimated, and that improving the evaluation process will involve substantial expenditure on research and experimentation. The agencies, in conjunction with the governments concerned, should be prepared to undertake this in the form of unified research activity under joint sponsorship. There would appear to be little merit in encouraging piecemeal experimentation on a project-by-project basis, nor should projects-or governments-be charged with the full costs of innovative research on effective evaluation systems. Such research might usefully begin with a comprehensive effort to document the experience of different PEUs and to produce a handbook of guidelines and procedures for their effective operation. 